be also rotated by means of the ligatures, bands and spars being attached to the individual teeth in the position necessary to bring about the required movement. There is no mere speculation as to the correct position of the teeth and the size of the arch and the amount of expansion resired, as means have been devised of measuring the teeth and from the measurement obtained the size of the arch and position in which to place the teeth can be almost accurately calculated and varies according to the size of the teeth in each individual case. The geometrical principles on which the movements of the jaws are based have also been studied and a fairly accurate basis for the discovery of the correct size of the arch in any case, with the teeth in position, can be obtained, and measures in a straight line from the distal buccal cusp of the right six year molar to the distal buccal cusp of the left six year molar from about $2_{\frac{1}{10} \delta}$ ths $-\frac{4}{100}$ ths of an inch in the upper jaw, and from $1{ }_{101}^{81}$ ths $-2 \frac{23}{100}$ ths of an inch in the lower jaw. The expansion arch if intelligently employed is wonderfully efficient in enlarging the arch in any direction and in the control of the teeth moved individually or collectively. It furnishes the most natural appliance to secure normal occlusion, for by it we can regulate the entire dental apparatus-something impossible in the use of the innumerable appliances that have been devised for the correction of symptoms only without regard for the laws of occlusion.

In treatment of cases of the second class where the lower arch is distal to normal the expansion arches and clamp bands are inserted as described. The force is then exerted from one or more small rubber ligatures which engage on sheath-hooks attached to the upper expansion arch in the canine region and over the ends of the tubes on the clamp bands on the lower molars. The force is reciprocal, acting directly on the molars, the result being to move the lower molars mesially and the upper molars distally. As the lower first molars are carried forward the bicuspids and canines are pushed in advance of them; the lower incisors are also carried forward, being ligated with wire ligatures to the anterior part of the expansion arch. After the upper molars have been moved distally into full normal occlusion it will be found that a space exists between the molars and second bicuspids. The clamp bands on the upper first molars are then removed and smaller clamp bands placed on the second bicuspids. The force of the rubber ligatures is again exerted in order to carry distally the bicuspids. A wire is made to engage the upper first and second bicuspids in order to effect their movement at the same time. Whilst moving the upper molars and bicuspids the arch is kept free from the incisors so as to allow the full force to come upon the former. When the teeth are well back into correct mesio-distal relations with the lower the arch is gradually adjusted to allow the force to be received by the upper incisors and canines, which in turn are soon moved into correct relation with their antagonists. The arch in both upper and lower jaw is usually inserted with a correct amount of outward spring to effect at the same time the required expansion. For the treatment of cases of the third class the above order with regard to the rubber ligatures and clamp bands is reversed.

To retain the teeth again the best device is probably a fixed apparatus. The simplest retainer for a single tooth is made by soldering a round wire to the labial or lingual surface of a band and cementing the band on the teeth. Several bands may be united for the same purpose to retain more than one tooth. An expanded arch can be retained by a stiff wire along the lingual sides of the teeth and soldered to a band on the first bicuspid and first molar teeth on each side. The incisors which have been moved forward or retracted are retained by a similar wire running along the lingual or labial surface of the teeth and soldered to bands on the first bicuspid teeth. The period of retention varies according to the amount of movement brought about and also upon the age of the patient, and may be any length of time between nine and 18 months. The nearer the attainment of normal occlusion in the correction of any case of malocclusion the less need there is for retention, the normal influence of the inclined planes as well as the other forces governing normal occlusion acting to preserve the positions obtained. With normal relations of the arches established, the jaws, the muscles of mastication, the cheeks and lips, and the facial lines will be in best harmony with the type peculiar to the individual, as a perfect profile requires normal occlusal relations.

Upper Wimpole-street, $\mathbf{W}$.

\section{ON A CASE OF MIGRATION OF THE CACUM PRODUCING OBSTRUCTION OF THE ASCENDING COLON.}

By JOHN BLAND.SUTTON, F.R.C.S. ENG., SURGEON TO THE MIDDLESEX HOSPITAL, LONDON, w.

(From Notes by the Surgical Registrar to the Middlesex Hospital, Somerville Hastings, F.R.C.S. Fing.)

WHEN the cæcum is provided with a long meso-cæcum it may lie in any region of the abdomen; perhaps the most unusual situation for a displaced cæcum to occupy is the left kidney pouch, behind the mesentery. When a cæcum migrates in this way it gives rise to a puzzling set of symptoms, as the following case will serve to illustrate.

A poorly nourished man, 48 years of age, came under my care in the Middlesex Hospital for abdominal pain and vomiting. A week before admission he had been seized suddenly with griping pains in the abdomen, particularly on the right side; these were sufficiently severe to confine him to bed and were followed by anorexia and vomiting. The vomit was bile-stained and watery. On admission the abdomen was somewhat distended, but moved evenly on respiration; no tumour could be felt and there was not much tenderness. The temperature ranged about $100^{\circ} \mathrm{F}$. As these signs indicated the existence of intestinal obstraction, coliotomy was performed. On making a free median incision several ounces of purulent fluid escaped and the intestines appeared inflamed and moderately distended. Attention was first directed to the right iliac fossa, but the cæecum and appendix were not there. A tense band of gut extended from the right extremity of the mesentery upwards and to the left, overlapped by mesentery and coils of small intestine; when traced upwards it led to the ileo-cæcal junction in the left kidney pouch. A loop, consisting of the last few inches of the ileum and the ascending colon with the cæcum and appendix, had been twisted on its own axis through half a circle and displaced upwards and to the left. The cæcum had become adherent in its new situation and when drawn down a large necrotic area with two perforations was seen, through which liquid fæces issued. The necrotic area was excised and the edges of the hole thus made in the gut were approximated with sutures. The free fluid in the abdomen was swabbed out, a large rubber tube was introduced into the pelvis, and the incision was closed with silk sutures. The man died 16 hours after the operation.

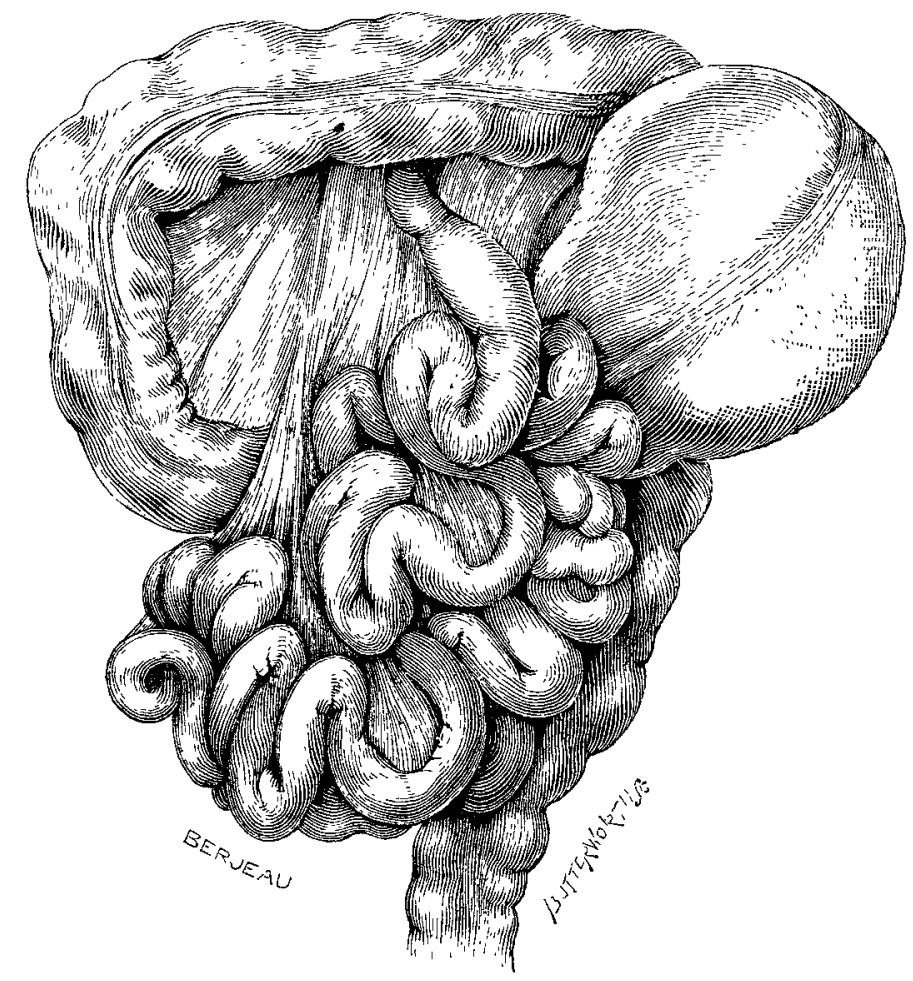

A diagram to represent the position of a cæcum 'which had undergone torsion and after passing bebind the mesenters undergone torsion and after passing behind the

The patient whose clinical history ard fate I have described came under my observation in October, 1906 . I was interested and much puzzled by the condition found at 
the operation; my interest was increased by reading a valuable contribution by Mr. Jonathan Hutchinson, jun., ${ }^{1}$ on Volvulus of the Entire Small Intestine and Ascending Colon. This communication was founded on a case which is in its leading features like the one which $I$ have endeavoured to describe, but Mr. Hutchinson fortunately saved his patient; he also made his paper valuable by furnishing an analysis of nine other similar cases of volvulus. $\mathrm{Mr}$. Harold W. Wil on has since published an account of a case of migration of the cæium producing obstruction of the ascending colon which occurred in St. Bartholomew's Hospital in the practice of $\mathrm{Mr}$. Harrison Cripps ${ }^{2}$ which resembles my case in its main features.

This complication connected with the cæcum is worth the attention of surgeons, as descriptions of it are not to be found even in monographs dealing with intestinal obstruc. tion. Its importance is obvious from the fact that the majority of the patients in whom it has occurred have died. Judging from a study of the recorded cases it would appear that the chief variations in the degree of the displacement depend upon the extent to which the twist or rotation involves the mesentery. For example, the extreme condition occurs in patients in whom the intestines, including the third part of the duodennm, the cæcum, and ascending colon, are attached to a common mesentery. When such an anatomical condition exists; and it is a recognised anomaly, the whole of the small intestines, the cæcum, and ascending colon may be concerned in the volvulus. In my patient the parts implicated included the terminal 12 inches of the ileum, the cæcum with the vermiform appendix, and half the ascending colon. The condition of the third portion of the duodenum was not noted either at the operation or post mortem. Daring the operation the absence of the cæcum from the rigbt iliac fossa was detected as soon as the abdomen was opened, because it is with me a matter of routine in operations for intestinal obstruction to ascertain the condition of the cæcum as the primary step after exposing the abdominal viscera.

I think the fatal nature of this form of volvalus is mainly due to delay on the part of hospital patients in seeking advice. The signs are not so urgent as in acute obstruction of the small intestine, and when the patients are admitted the obstruction may not be absolute, for enemata bring away small quantities of flatus. Abdominal distension is not a marked feature. In the case under my own care the diagnosis seemed to lie for the first few hours between perforation of the appendix and intestinal obstruction ; then the indications of obstruction prevailed. The signs of perforation were not counterfeit, for, as has already been mentioned, there were two holes in the wall of the crcum. The man was gravely ill at the very hour of his admission.

Brook-street, W.

\section{NOTES ON SCURVY IN SOUTH AFRICA, 1902-1904.}

\section{BY DUNOAN MAOKENZIE MACRAE, M.A., M.B., СH.B. GLASG.,}

LATE CIVIL SURGEON, SOUTH AFRICAN FIELD FORCE.

THE earliest information which emerges from the twilight of antiquity in regard to scurvy is perhaps that supplied to us by Pliny who states that a disease which was cured by eating a certain vegetable prevailed in the army of Germanicus. Thucydides, who has been styled "the greatest historian that ever lived," described the horrors of the plague at Athens (B.C. 430) in words of lurid fire; but, unfortunately, no such writer has left us a record of scurvy as it existed among the ancients, although we may well believe that the conditions under which they often lived and waged war were favourable to outbreaks of the disease on a large scale. There is evidence, more or less reliable, that in mediæval times it frequently broke out in beleaguered towns and garrisons, but it is only when we approach the records of early maritime enterprise that we stumble upon anything like a definite description of its nature and occasional virulence. The sailors of Bartholomew Dias (1486), Vasco da Gama

1 Clinical Journal, June 5th, 1907

2 St. Bartholomew's Hospital Reports, vol. xliii., p. 147.
(1496), Raymond (1591), and Lancaster ${ }^{1}$ (1601), in their early voyages round the South African promontory, suffered more or less from scurvy. The best accounts of it, however, are to be found in the narratives of such navigators as Jacques Cartier, Dampier, Anson, and Captain Cook. Lancaster and Captain Cook, in their longer voyages, proved the efficacy of lemon juice as a remedy in the disease and Dampier records with some enthusiasm the benefits resulting to his crews from a short stay on the island of Juan Fernandez (1683), where they were fed on vegetables and goats' flesh, "a regimen which," to use his own words, "proved very beneficial." Anson's ${ }^{2}$ account, however, is less glowing, for when he landed his scorbutic sailors on the same island in 1739 he relates how, although many greatly benefited eventually, "the disease continued unabated for 20 days" and in some cases assumed an intractable form. The first clear and scientific record of scurvy is to be found in the writings of Lind (1797), and it is largely due to his insight and the efforts of Sir Gilbert Blane that the disease has been banished from the navy and mercantile marine.

It is not at present intended to do more than briefly to summarise and comment upon the phenomena of the disease as observed among the kaffirs during, and for some time after, the South African war. Through the courtesy of the officers of the Royal Army Medical Corps, the writer, while stationed at the Military Hospital (No. 8), Bloemfontein, during the years 1902-04, was permitted to take charge of all kaffirs admitted suffering from scurvy, and it is on the observations then made, in conjunction with LieutenantColonel C. Birt, R.A.M C., and Captain J. W. West, R.A.M.C., in regard to its symptoms, behaviour under treatment, and the condition of the blood on examination that the following remarks are based.

Two hundred natives suffering from scurvy were treated in No. 8 Hospital during the above-mentioned period, and of this number 13 died. But before describing the most striking symptoms, although the writer is unwilling to encumber this article with exhaustive references to the literature of the subject, it may be well to mention the several theories which have been at different times advarced in explanation of this disease. Garrod believed that it was due to a deficiency of potassium salts in the food. Ralfe ascribed it to the absence of regetable acids, such as malates, citrates, and lactates, causing diminished alkalinity of the blood. Sir A. E. Wright describes it as "an acid intoxication which eventuates in a defect of blood coagulability" and some have supposed it to be due to a specific micro-organism. The most recent suggestion, due to Professor Torup of Christiania, is that the disease is a kind of ptomaine poisoning resulting from eating tainted meat. The experiences of $\mathrm{Mr}$. Jackson and others in the Arctic regions, and the experiments of Dr. R. J. Harley in support of their observationsviz., that those living exclusively on fresh raw meat escaped the disease under the most trying circumstances, while those supplied with lime juice suffered from it-would seem to throw discredit on the time-honoured view that fresh vegetables and lime juice were efficient preventives against it. ${ }^{3}$

The pendulum of scientific thought was thus suddenly swung to the other extreme-a not uncommon error in the history of human speculation; but it must be admitted that the problem of the etiology of scurvy still remains unsolved.

Signs and symptoms.-These, in the main, conformed to the descriptions found in text-books. Petechial ecchymoses of the skin, hæmorrhagic swellings in the neighbourhood of joints (more especially the knee-joints), ulcers of the buccal cavity, and a brawny induration of the anterior aspect of the legs were the prevailing signs of the disease. Serious complications, such as hæmothorax and sero-sanguinolent effusions into the pericardial sac, were not uncommon and always terminated fatally; but the spongy condition of the gums, usually regarded as an infallible sign of scurvy, was by no means a constant characteristic in the cases under consideration, so that some difficulty was at times experienced in arriving at a correct diagnosis. It was absent even in some of the most serious cases admitted to hospital. A striking feature in the disease was the almost universal complaint of pain in the ohest. This pain was usually referred

1 Theal's History of South Africa (1486-1691), Chapter I. 2 Dampier's Voyages: Anson's "Voyages Round the World," by $\mathbf{R}$

3 Article by Dr. W. H. Neale in the Practitioner, 1896. 